\title{
Muséologies
}

Les cahiers d'études supérieures

muséologies

\section{Musealia des cultures de tradition orale}

\section{Virginie Soulier}

Volume 3, numéro 1, automne 2008

URI : https://id.erudit.org/iderudit/1033581ar

DOI : https://doi.org/10.7202/1033581ar

Aller au sommaire du numéro

\section{Éditeur(s)}

Association Québécoise de Promotion des Recherches Étudiantes en Muséologie (AQPREM)

ISSN

1718-5181 (imprimé)

1929-7815 (numérique)

Découvrir la revue

Citer cet article

Soulier, V. (2008). Musealia des cultures de tradition orale. Muséologies, 3(1), 76-99. https://doi.org/10.7202/1033581ar

\section{Résumé de l'article}

À la suite du colonialisme, la redéfinition des relations entre Occidentaux et Autochtones engendre une réévaluation de la signification et de la présentation de leur patrimoine dans les musées européens et américains. Après quoi, une tendance à « l'artialisation » se profile, rejetant la polysémie de l'objet multiple et usuel au profit de l'objet unique présenté à la manière de l'oeuvre d'art. Face aux dérives possibles de cette tendance, Virginie Soulier démontre dans cet article que plusieurs musées adoptent a contrario une approche " plurivocale » et " authentique » où la multiplication des voix et des visions est privilégiée, plutôt que le seul aspect esthétique, propre à la sensibilité occidentale.
Tous droits réservés @ muséologies Les cahiers d'études supérieures, 2008
Ce document est protégé par la loi sur le droit d'auteur. L’utilisation des services d'Érudit (y compris la reproduction) est assujettie à sa politique d'utilisation que vous pouvez consulter en ligne.

https://apropos.erudit.org/fr/usagers/politique-dutilisation/ 
Article trois

Musealia des cultures de tradition orale

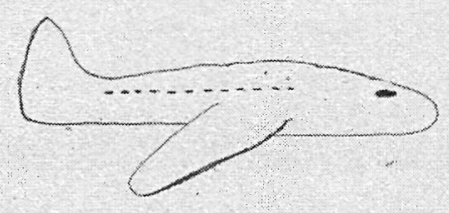


À la suite du colonialisme, la redéfinition des relations entre Occidentaux et Autochtones engendre une réévaluation de la signification et de la présentation de leur patrimoine dans les musées européens et américains. Après quoi, une tendance à «l'artialisation" se profile, rejetant la polysémie de l'objet multiple et usuel au profit de l'objet unique présenté à la manière de l'œuvre d'art. Face aux dérives possibles de cette tendance, Virginie Soulier démontre dans cet article que plusieurs musées adoptent a contrario une approche "plurivocale» et " authentique" où la multiplication des voix et des visions est privilégiée, plutôt que le seul aspect esthétique, propre à la sensibilité occidentale.

VIRGINIE SOULIER EST ÉTUDIANTE AU DOCTORAT DANS LE PROGRAMME INTERNATIONAL EN MUSÉOLOGIE, MÉDIATION, PATRIMOINE, UNIVERSITÉ DU QUÉBEC À MONTRÉAL (UQAM) ET UNIVERSITÉ D'AVIGNON ET DES PAYS DE VAUCLUSE (UAPV). SON PROJET DE RECHERCHE PORTE SUR LES EXPOSITIONS MUSÉALES ÉLABORÉES EN COLLABORATION AVEC LES PREMIÈRES NATIONS. ELLE EST TITULAIRE D'UNE MAITRISE EN MUSÉOLOGIE DE LUNIVERSITÉ DU QUÉBEC À MONTRÉAL (UOAM) (LES MUSEALIA DES CULTURES DE TRADITION ORALE, 2006) ET D'UN MASTER EN HISTOIRE DE LART DE L'UNIVERSITÉ DE PERPIGNAN VIA DOMITIA (MODERNISMEET PRIMITIVISME, LE TOTÉMISME À TRAVERS LES FEUVRES D'EMILY CARR, 2004). SON TRAVAIL DIRIGÉ DE MAîTRISE A ÉTÉ SÉLECTIONNÉ PAR LE PROGRAMME DE MUSÉOLOGIE DE L'UOAM POUR LE PRIX ROLAND ARPIN. CET ARTICLE PRÉSENTE UN COMPTE-RENDU DE SON TRAVAIL DIRIGÉ. [virginie@virginiesoulier.com] 
[1]

<http://www.unesco. org/culture/ich/index. php?pg $=00006>$ (consulté en juin 2008).

[2]

$<$ http://www.un.org/esa/ socdev/unpfii/fr/drip.html>

(consulté en juin 2008).

[3]

"L'Artialisation» est un terme élaboré par Alain Roger dans Court traité du paysage (Paris: Gallimard, 1997) emprunté à l'écrivain Michel de Montaigne pour désigner une mise en scène de la nature qui modèle le regard collectif. La théorie de l'auteur sur la représentation du paysage est ainsi définie dans l'ouvrage: «|l n'y a pas de beauté naturelle, ou plus exactement, la nature ne devient belle à nos yeux que par le truchement de l'art", signifiant que notre perception esthétique est médiatisée par une opération artistique. Ce terme a été repris dans un appel à communication d'un colloque du musée du quai Branly à Paris qui a eu lieu les 21-23 juin 2007, où il signifiait: mettre en avant les valeurs esthétiques. Ce colloque a été organisé par le CFHA (Comité

français d'histoire de l'art)

et le musée du quai Branly sous l'égide du CIHA (Comité international d'histoire de l'art), en partenariat avec l'INHA (Institut national d'histoire de

l'art). L'appel de communication portait sur «les relations entre I'histoire de l'art et l'anthropologie au lendemain de l'ouverture à Paris du musée du quai Branly (juin 2006) qui regroupe les collections du Laboratoire d'ethnologie du Musée de l'Homme et du Musée des Arts d'Afrique et d'Océanie, ancien Musée des Colonies».
En 2005-2006, le gouvernement français tentait de redéfinir les relations qu'il entretenait avec ses colonies durant la période coloniale et leurs impacts positifs, construisant ainsi une nouvelle histoire. Le premier ministre du Canada, Stephen Harper, a présenté, le 11 juin 2008, ses excuses officielles aux anciens élèves des pensionnats indiens créés dans le cadre d'une politique d'assimilation des Autochtones. La France a signé la Convention pour la sauvegarde du patrimoine culturel immatériel de l'Organisation des Nations Unies pour l'éducation, la science et la culture (UNESCO) ${ }^{[1]}$ et la Déclaration sur les droits des peuples autochtones de l'Organisation des Nations Unies $(\mathrm{ONU})^{[2]}$, alors que le Canada, où les Premières Nations vivent in situ, ne s'est engagé pour aucun de ces textes qui visent à protéger les cultures et à restituer le droit à la parole à ces peuples, entre autres. La France s'affiche avec le nouveau musée présidentiel du quai Branly et avec ce que l'on pourrait appeler une tendance à " l'artialisation " ${ }^{(3)}$, selon l'expression de cette institution, consistant à unir et à présenter les objets par une approche esthétique. Élise Dubuc et Laurier Turgeon ont identifié d'autres tendances liées à deux types de participation des Amérindiens dans l'élaboration des expositions en Amérique du Nord: les approches " plurivocale " et "authentique» " ${ }^{[4]}$. Il semblerait aussi, d'après des observations sur le terrain, que la perspective artistique continue de se développer au Canada sur l'ensemble des musées sans qu'elle ne soit attestée.

À partir de ce croisement d'observations d'ordres politique et patrimonial, on se rend compte que l'ère du post-colonialisme entraîne un travail de mémoire, des réformes, des interrogations quant aux mises en représentation de ces peuples par les Occidentaux ainsi qu'une réflexion sur la mise en place de nouveaux rapports sur le plan culturel. 
Face à cette perspective artistique, l'objectif de la recherche est d'étudier l'origine et l'évolution de cette approche. Les buts sont d'analyser son développement dans les musées canadiens qui collaborent avec les Premières Nations et d'essayer d'en faire émerger une logique opérée au sein des musées. L'analyse porte ainsi sur les statuts des objets muséaux, les facteurs qui les déterminent et les enjeux qui y sont rattachés. Le statut de l'objet reflète la démarche et les points de vue des muséologues, mais aussi les priorités et les orientations des musées. Il rend compte de la place, du rôle, des signifiés et des valeurs attribués à l'objet dans son contexte muséal.

\section{"Musealia des cultures de tradition orale"}

Avant de poursuivre, il est important de clarifier et d'analyser la terminologie la plus appropriée pour déterminer l'ensemble des biens culturels provenant des peuples anciennement colonisés de culture orale, biens qui ont été récupérés et acquis par les musées depuis le colonialisme jusqu'à nos jours. En effet, personne ne s'entend encore sur l'utilisation d'un même qualificatif, les termes variant selon les points de vue des discours sociaux, artistiques et scientifiques ${ }^{[5]}$. De plus, vouloir rassembler sous un même vocable un vaste ensemble de communautés est assez délicat, notamment à l'heure de la reconnaissance des diversités culturelles ${ }^{[6]}$.

Comment est-il possible de regrouper ces objets provenant des Amériques, de l'Océanie et de l'Afrique sur une période de plus de cinq siècles?

Ce sont premièrement des objets de collections muséales ayant un parcours, une histoire et un statut liés à ces institutions. L'institutionnalisation d'un objet confere à ce dernier le statut de musealia ${ }^{[7]}$ ou de muséalie ${ }^{[8]}$. L'objet $^{[9]}$ est ce qui s'offre au regard, ce qui s'offre en spectacle ${ }^{[10]}$. Un musealia est, par contre, une vraie chose sélectionnée et reconnue selon des critères d'importance patrimoniale et qui revêt des valeurs matérielles et immatérielles exceptionnelles pour la communauté, dans un contexte culturel particulier. L'objet de musée est donc protégé, conservé et mis en valeur ${ }^{[11]}$. Ce sont des objets de collections, moins considérés comme des choses (du point de vue de leur réalité physique) que comme des êtres de langage (dignes d'être conservés et présentés) et des supports de pratiques sociales.

Deuxièmement, ces objets pouvant se trouver dans tous types et toutes catégories de musées, tant de sites que disciplinaires, thématiques commémoratifs ou autres, la qualification doit donc rester potentiellement transversale à toutes les institutions, quels que soient leur mandat ou leurs disciplines.

\section{[4]}

La première tendance est l'approche "plurivocale" qui intègre les voix de tous les groupes culturels concernés, permettant de créer une représentation polyphonique de leur culture. La deuxième approche tend à faire ressortir la "voix authentique des Amérindiens, en excluant les influences occidentales. (DUBUC, Élise et Laurier TURGEON. «Musées et Premières Nations, La trace du passé, l'empreinte du futur *. Anthropologie et Sociétés, vol. $28, n^{\circ} 2,2004$, p. 11.) [5]

Les termes souvent employés sont «|'art non occidental» et « l'art extra-occidental», mais ils impliquent une approche dichotomique et artistique et un point de vue occidental: "nous et vous" ou "nous vous interprétons ". Comme l'écrivent James Clifford et Jean Baudrillard, les collections ne reflètent que nous-mêmes. En outre, les communautés en question ne partagent pas forcément les mêmes concepts et les mêmes paradigmes artistiques. Par ailleurs, qu'entendons-nous par l'Art? II y a eu beaucoup d'écrits à ce sujet, mais aucune définition réellement liée à ces objets n'a été acceptée et légitimée par les muséologues de manière unanime. Depuis les années 1960, sous l'instigation de Jacques Kerchache, notamment, ces objets sont considérés comme des «arts premiers *, mais ce terme provient du milieu de l'art: des artistes et des marchands. Dans la mesure où la qualification «premier * fait débat face à la proximité sémantique avec "primitif», nous évitons cet emprunt. DAVALLON, Jean. «Le musée est-il vraiment un média? . Publics et Musées, vol. 2, 1992, p. 104. 
<http://unesdoc.unesco.org/ images/0012/001271

$/ 127160 \mathrm{~m} . \mathrm{pdf}>$ (consulté en juin 2008).

DAVALON, Jean. "Le musée est-il vraiment un média ? ". Publics et Musées vol. 2, 1992, p. 104

[8]

Musealia est un terme d'origine latine. "Le terme musealia, en français muséalie, a été proposé en 1970 par Zbyneck

Stransky, en équivalence à celui d'objet de musée et, plus récemment, dans une perspective plus philosophique,

J.L. Déotte parle de suspens."

(DE BARY, Marie-Odile et Jean-Michel TOBELEM. "Objet de musée". Manuel de muséographie, Petit guide à l'usage des responsables de musée. Biarritz: Séguier, Option culture, 1998, p. 236-237.)

[9]

BERGERON, Yves.

«De la notion privée d'héritage matériel au concept universel et extensif de patrimoine Actes du colloque Médias et patrimoine. Le rôle et l'influence des médias dans la construction d'une mémoire collective. Québec: Institut du patrimoine culturel, 2003 , p. $45-52$.

[12]

Ce terme ne relève pas d'une opinion, d'une théorie interprétative particulière ou conjoncturelle des disciplines artistiques ou anthropologiques, même s'il soulève le fait qu'il provient d'une culture et la représente. Cette nomination relève davantage du domaine de la muséologie.
Enfin, il est nécessaire que la dénomination caractérise un aspect culturel de ces peuples par rapport aux missions culturelles intrinsèquement reliées aux musées.

Mettant ainsi rapidement l'accent sur ces problèmes terminologiques, nous proposons d'utiliser une nouvelle épithète: musealia des cultures de tradition orale, soulignant ainsi le fait que ces collections aient été sélectionnées, acquises et conservées par des institutions muséales et que ces objets aient été collectés dans des territoires ayant cette tradition en commun. Nous emploierons le terme Musealia par souci de concision ${ }^{[12]}$

Le cadre d'analyse se structure en trois parties:1) l'histoire des Musealia, l'évolution des regards occidentaux posés sur ces objets et leurs statuts successifs; 2) les rôles et les responsabilités actuels des musées vis-à-vis des Musealia afin d'élaborer une typologie telle qu'un idéal-type muséologique; 3) les statuts actuels de ces objets dans les musées canadiens pour mettre en relation les statuts des objets dans les fonctionnements interne et externe et par rapport à la typologie élaborée en deuxième partie.

Le travail de terrain a été réalisé sur la côte nord-est du Canada. La recherche se limite à deux secteurs géoculturels les plus exposés : côte nord-ouest, avec notamment la nation haïda, et des régions arctiques avec les communautés inuit ${ }^{[13]}$. Des entrevues auprès de conservateurs de musées et des analyses formelles d'expositions ont été réalisées ${ }^{[14]}$.

\section{L'évolution des statuts des Musealia}

\section{et les débuts de l'approche artistique}

\section{Du XV' siècle au XVII ${ }^{e}$ siècle : l'introduction des objets curieux des sauvages dans le monde occidental}

C'est à la fin du Moyen Âge, au moment des grandes découvertes, grâce aux progrès de la navigation, que l'Europe en quête d'or et d'épices s'ouvre réellement aux autres continents. Les premiers objets exotiques qui débarquent dans les cours princières et royales proviennent de l'Afrique noire, des comptoirs portugais, des Amériques avec les échanges avec les navigateurs espagnols, puis de l'Amérique du Nord où les Français et les Anglais sont étonnés par le savoir-faire des Amérindiens devant les objets en plumes et les parures. Par contre, les objets rituels, sacrés et cultuels sont souvent détruits ou condamnés moralement.

Les rois et les princes, les riches marchands et les médecins sont les premiers à posséder ces objets exotiques et étranges au XV' siècle et au début du 
$\mathrm{XVI}^{\mathrm{e}}$ et ils créent leurs propres cabinets de curiosités. Ceux-ci sont composés d'objets hétéroclites, aussi bien des naturalia, des artefacts, que des écofacts. La soif de curiosité et la fierté de montrer à ses égaux des objets rares, précieux et étranges enrichissent le désir de reconstruire le monde en miniature dans leur palais. Une sorte de premier marché d'art se met également en place en Afrique face à cet engouement pour les objets exotiques.

On pourrait dire qu'une première reconnaissance artistique s'amorce pendant la Renaissance avec l'intérêt que porte alors le peintre et théoricien allemand Albrecht Dürer à ces merveilles. À la fin de l'été 1520, lors de son voyage aux Pays-Bas, Dürer découvre des objets en or rapportés du Mexique pour Charles Quint ${ }^{[15]}$.

À la fin du XVIII ${ }^{\mathrm{e}}$ siècle, les "sauvages " sont considérés comme "naturels", ne possédant pas de civilisation. Les objets sont placés sur le même plan qu'une curiosité géologique et définis sous le terme de naturalia, en opposition aux œuvres d'art classique classées comme artificialia.

Les cabinets de curiosités cèdent leur place graduellement aux premiers musées qui ont de nouveaux enjeux et de nouvelles vocations : le laboratoire d'observation à buts scientifique et pédagogique. Le British Museum ouvre ses portes en 1753 et se voit doté dès 1780 d'une galerie des Mers du Sud où il expose des pièces océaniennes et américaines.

\section{Le XIX' siècle : les musées d'ethnographie, d'histoire naturelle, "les spécimens primitifs " et «les artefacts culturels "}

Cette période se caractérise par les suffixes en "ismes " : colonialisme, industrialisme, évolutionnisme, darwinisme et diffusionnisme, où la valorisation des qualités formelles des Musealia est moins sous-jacente.

En 1859, Charles Darwin publie Del'origine des espèces au moyen de la sélection naturelle ${ }^{[16]}$. Lévolutionnisme biologique sert d'assise à l'évolutionnisme culturel et social du philosophe britannique Herbert Spencer lié à l'idéologie

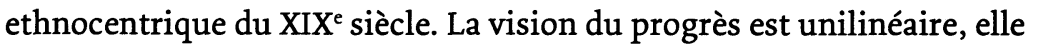
établit différents stades d'évolution de l'humanité, du primitif, c'est-à-dire de l'état premier de l'évolution, au civilisé, à celui qui vit dans une cité avec des règles, des hiérarchies et des techniques évoluées. Le Sauvage devient un Primitif et ses objets deviennent des témoignages dans le présent de ce que furent les ancêtres des Européens, mais aussi les jalons de l'ethnologie. La primitivité des techniques est une étape transitoire dans l'évolution; quand cette dernière stagne, elle est un indicateur de disparition des producteurs. Considérant que les cultures primitives sont en voie de disparition, des campagnes de collecte sont organisées. Le développement des musées ethnographiques entraîne de nombreuses aliénations.
[13]

Ce choix se justifie par plusieurs faits actuels importants. Une nouvelle acquisition majeure a été réalisée au Québec: la collection d'art inuit Brousseau au Musée national des beaux-arts du Québec. Cinq expositions temporaires importantes ont eu lieu à l'été 2006, dans des musées de typologies différentes: l'exposition de la collection de George Mercer Dawson au Musée McCord à Montréal: L'art haïda Les voies d'une langue ancienne; l'exposition d'un artiste haïda: Robert Davidson. Au seuil de l'abstraction au Musée McCord à Montréal; l'exposition Emily Carr, nouvelles perspectives, qui fait également hommage à l'exposition de Marius Barbeau de 1927 au Musée des beaux-arts du Canada; et l'exposition Brian Jungen au Musée d'art contemporain de Montréal. Finalement, le Musée des beaux-arts de Montréal recevait l'exposition Itukiagâtta sur l'art inuit et a refondé, pour l'occasion, sa propre exposition permanente sur cet art. 


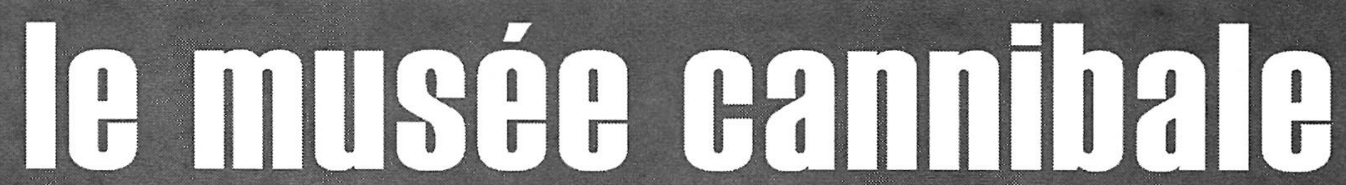
musée d'ethnographie neuchâtel

\section{$9.03 .02-2.03 .03$}

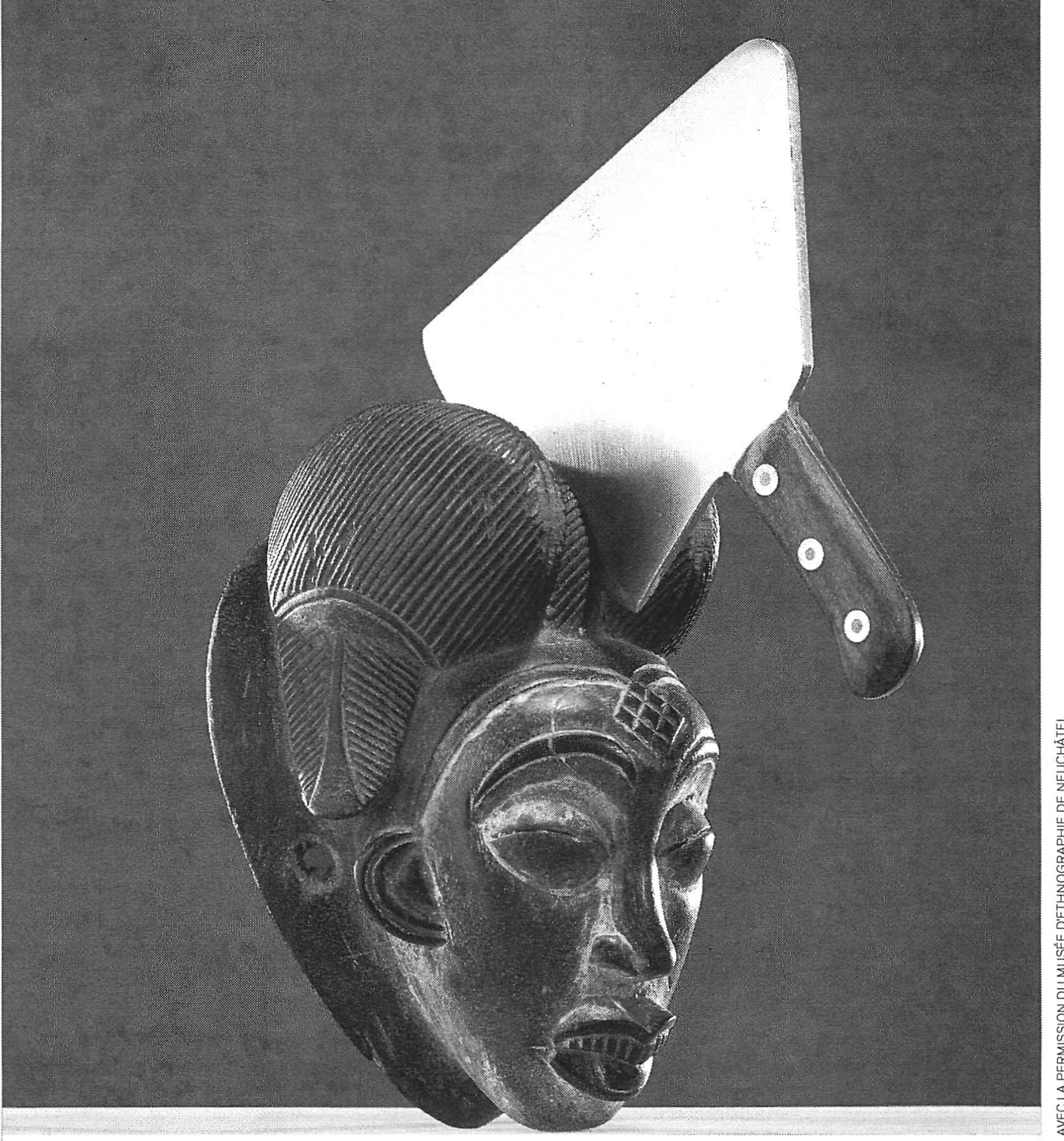


Les expositions universelles se développent également pour traduire l'hégémonie occidentale. Elles sont l'occasion de mettre en valeur les productions nationales ainsi que les victoires impériales à partir des trophées martiaux. Les grandes manifestations plus « exotiques " présentent les sauvages comme des phénomènes de foire dans des "zoos humains", selon l'expression de Pascal Blanchard et ses collaborateurs ${ }^{[17]}$, où l'indigène est lui-même un expôt.

Les Musealia sont porteurs du discours colonial et édifient « la mission civilisatrice» des pays impériaux.

Ils sont ensuite présentés dans une approche naturaliste et entrent également dans les musées de synthèse. Le musée du Trocadéro est destinéà renseigner sur « la connaissance exacte du degré de culture, des usages, des mœurs, des idées religieuses et de l'industrie de ces peuples " ${ }^{[18]}$. Ce musée ethnographique ouvre en 1880 , avec à sa tête le naturaliste Ernest Théodore Hamy ${ }^{[19]}$. Les matériaux et les sociétés sont classés selon les typologies de cette discipline. La problématique fondamentale de cette époque est l'évolution de l'humanité.

À la fin des années 1880 , l'évolutionnisme est de plus en plus critiqué. La vision unilinéaire, du simple au plus complexe de l'évolution de l'humanité, semble trop simpliste, n'expliquant pas toutes les modalités de l'évolution dans un contexte environnemental. De plus, les sociétés s'influencent entre elles. Les anthropologues estiment que non seulement il faut considérer les adaptations dans l'environnement, mais aussi les interrelations entre les sociétés. Franz Boas ${ }^{[20]}$ défend l'idée selon laquelle les études comparatives doivent être conduites dans un cadre géographique et multiculturel. C'est ainsi que le diffusionnisme cherche à établir une méthode plus objective pour définir les critères et les lois permettant de distinguer des moments successifs à travers les processus temporels de la diffusion. Boas met en place de nouvelles méthodes de présentation des objets. Toujours considérés comme des témoins, ces objets sont exposés de façon à leur rendre une signification dans leur contexte culturel et ils sont mis en relation avec l'ensemble des artefacts de la culture en question. Les objets témoignent donc des différences culturelles, mais aussi des acculturations. Cette rupture privilégie le sens plus que la forme ou la fonction. Les objets ne sont plus rassemblés selon leur usage, mais par culture et selon leur sens.

Les deux mouvements de classification développés au sein de la société, l'évolutionnisme et le diffusionnisme, sont également appliqués et s'entrecroisent le plus souvent dans les présentations muséales durant cette période.

\section{[14]}

Les conservateurs interviewés sont: Daniel Drouin du Musée national des beaux-arts du Québec; Guislaine Lemay du Musée McCord à Montréal; Réal Lussier du Musée d'art contemporain de Montréal; Charles C. Hill et Denise Leclerc du Musée des beaux-arts du Canada à Ottawa; Jacques Desrochers du Musée des beaux-arts de Montréal; Judy Thompson et Norman Vorano du Musée canadien des Civilisations à Gatineau; et le collectionneur Raymond Brousseau du Musée Brousseau d'art inuit à Québec. Les expositions temporaires étudiées sont: L'art haïda. Les voies d'une langue ancienne, au Musée McCord à Montréal; Robert Davidson. Au seuil de l'abstraction, au Musée McCord à Montréal; Emily Carr, nouvelles perspectives, au Musée des beaux-arts du Canada; Brian Jungen, au Musée d'art contemporain de Montréal; et Itukiagâtta, au Musée des beaux-arts de Montréal. Les expositions permanentes analysées sont: L'art d'ici, au Musée des beaux-arts du Canada; Itukiagâtta, au Musée des beaux-arts de Montréal; Simplement Montréal: coup d'cil sur une ville unique, au Musée canadien des Civilisations; et La salle des Premiers Peuples et La grande galerie, au Musée canadien des Civilisations. 
[15]

Dürer note dans son journal:

"Aussi loin qu'aille ma

mémoire, je n'ai jamais vu de ma vie aucune chose qui m'ait à ce point ravi le cœur.

II s'y trouvait des œuvres d'un art vraiment prodigieux et je fus émerveillé de la subtile ingéniosité des hommes vivant dans ces lointaines contrées. Je ne puis trouver les mots pour dire tout ce que je vis là.n (FEAU, Étienne, Pascal MONGNE et Roger BOULAY, Arts d'Afrique, des Amériques et d'Océanie. Paris: Larousse, 2006, p. 14.)

[16]

DARWIN, Charles. On the Origin of Species by Means of Natural Selection. London: John Murray, 1839.

[ $\pi$ ]

BANCEL, Nicolas,

Pascal BLANCHARD, Gilles BOËTSCH, Éric DEROO et Sandrine LEMAIRE (dir.). Zoos

humains. Au temps des exhibitions humaines. Paris: La Découverte / Poche, 2004, $486 p$.

[18]

DEGLI, Marine et

Marie MAUZE, Arts premiers, Le temps de la reconnaissance.

Paris: Découvertes Gallimard / Réunion des musées nationaux, Histoire, 2000, p. 58.

[19]

Musée d'ethnologie Neuchâtel (MEN). Le musée cannibale.

Neuchâtel: MEN, Musée d'ethnographie, 2002, p. 65.

[20]

Franz Boas est un anthropologue américain qui a rejeté

l'évolutionnisme et qui a appliqué le diffusionnisme.

II a développé le concept du relativisme culturel.

Il est l'auteur de Primitive Art

(Cambridge, MA: Harvard University Press, 1927). II introduit et met en valeur dans son ouvrage la dimension artistique en anthropologie des objets des sociétés non occidentales.

\section{Le XX' siècle et les « arts premiers:}

\section{les musées de société et de beaux-arts"}

Un tournant s'amorce avec les peintres expressionnistes allemands, puis des artistes de Paris - avec la "révolution moderniste associée à Picasso " -, de Berlin, de Prague et de Saint-Pétersbourg, faisant émerger l'appropriation esthétique des Musealia, leur donnant un nouveau statut artistique et créant, dans les années 1920, le mouvement du primitivisme en art. Les marchands d'art présentent ces objets dans les galeries comme des œuvres artistiques, sous l'instigation des artistes. En 1919, Picasso organise la première exposition importante d'arts primitifs à la Galerie Devambez, à Paris : Première exposition d'art nègre et d'art océanien. Les surréalistes, dans les années 1930, s'approprient à leur tour "l'art nègre " et n'hésitent pas à présenter des œuvres d'artistes contemporains en dialogue avec des arts d'Océanie et d'Amérique du Nord. Aussi voit-on, en 1926, Man Ray et objets des îles et, en 1927, Yves Tanguy et objets d'Amérique. En 1932, le sculpteur Jacques Lipchitz participe au réaménagement d'une salle au Musée du Trocadéro : la salle du Trésor. Il crée des socles pour des objets qui sont alors présentés comme de véritables chefs-d'œuvre.

Un changement apparaît également du côté des ethnologues et des théoriciens de l'art, avec par exemple Leo Frobenius ou Carl Einstein ${ }^{\text {[21]. }}$ Il se développe dès lors un véritable engouement pour l'exotisme, allant de la mode pour le jazz à la curiosité pour l'art nègre. Félix Fénéon pose alors la question : «L'art nègre doit-il entrer au Louvre? » ${ }^{[22]}$.

Le XX ${ }^{e}$ siècle est le siècle du Beau, mais aussi celui de la Culture. Alors que le primitivisme alimente l'art contemporain, les scientifiques continuent de mener des enquêtes de terrain et des études comparatives. Les études se diversifient, de la description formelle à la contextualisation sociale. L'enjeu est de déterminer si l'on doit traiter les objets par grands types indépendamment des cultures ou si, au contraire, on doit privilégier l'étude de l'ensemble des objets liés à une culture ou à un ensemble de cultures proches les unes des autres ${ }^{[231}$. L'objet sert finalement à représenter et à caractériser le style de la tribu d'origine. Les musées présentent donc les objets dans leur contexte culturel en valorisant l'aspect esthétique; c'est l'anthropologie qui enrichit à son tour l'approche artistique.

En 1927, Franz Boas publie Primitive Art ${ }^{[24]}$. Il donne une définition de ce qu'est l'Art et il décrit les particularités graphiques et plastiques de chaque culture primitive. Il établit des regroupements stylistiques et symboliques dans les aires culturelles (délimitées selon des critères linguistiques). Il combine ses méthodes anthropologiques et les approches artistiques, sur le plans formel et iconographique. Il associe également les biens immatériels aux symboliques matérielles. 


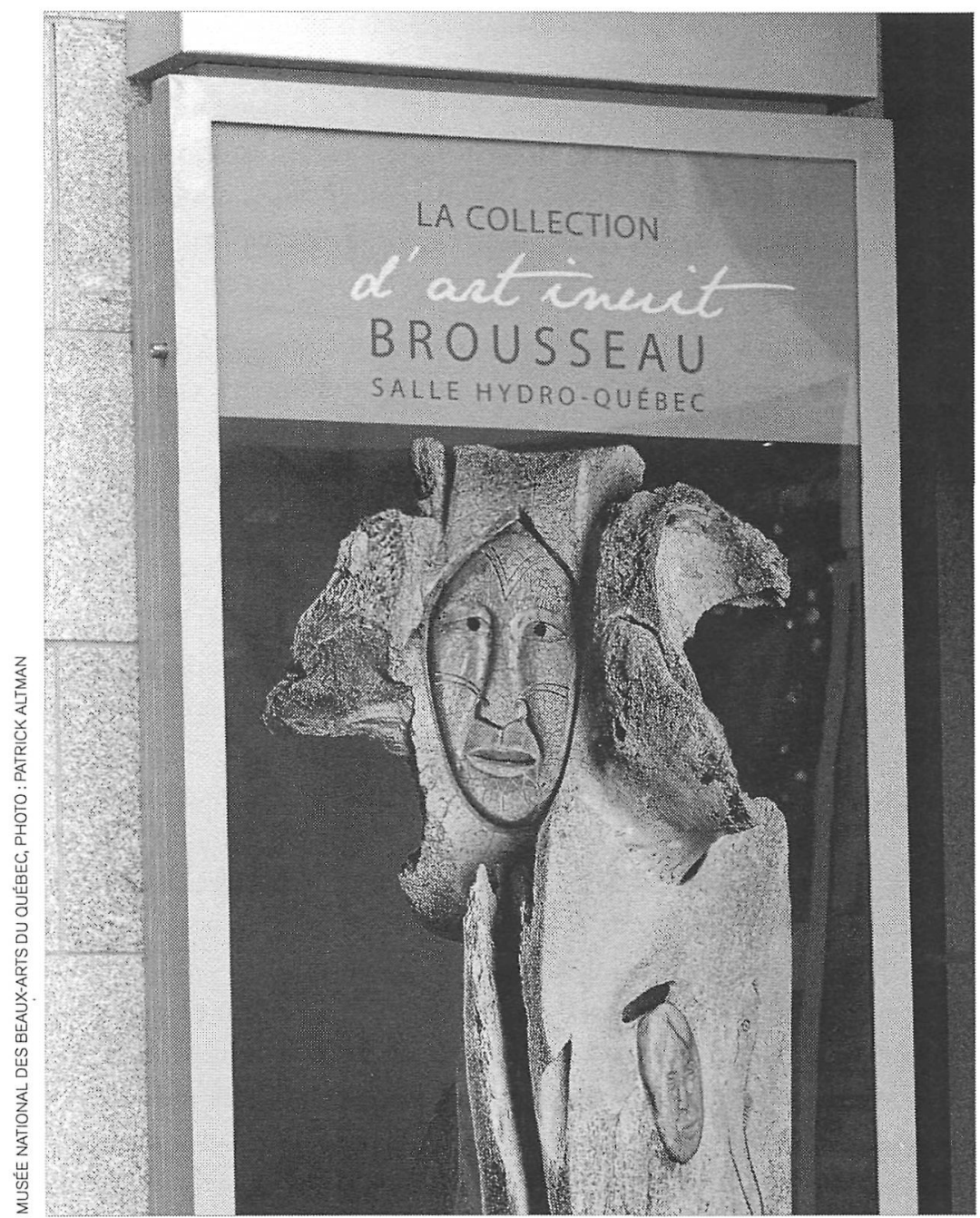

De l'autre côté de l'Atlantique, une certaine consécration artistique des Musealia voit également le jour et elle sera suivie en Europe, au détriment, comme le soulignent Emmanuel Desveaux et Marine Degli, de l'aspect technique des objets ${ }^{2251}$. À titre d'exemple, le Museum of Modern Art de New York organise en 1935 l'exposition African Negro Art, de la collection du galeriste Charles Ratton.

Les temps de la décolonisation accentuent cette perspective artistique et entraînent de nombreux changements pour les musées. André Malraux veut créer un musée d'art, le Musée des arts africains et océaniens (MAAO): le premier à se donner pour vocation de présenter des objets ethnographiques dans des vitrines de type beaux-arts, s'attachant à montrer avant tout l'aspect esthétique des objets. Le grand collectionneur Jacques Kerchache participe

\section{[21]}

Le théoricien d'art Carl Einstein a écrit Negerplastik signifiant la sculpture nègre, paru en 1915 (Kunst und Künstler, $\left.n^{\circ} 13\right)$. II y analyse l'art africain sur le plan formel sans recourir à des comparaisons avec un art occidental, en affirmant déjà le statut d'œuvre de ces objets dits ethnographiques. II s'attaque aussi aux concepts du primitivisme et aux théories évolutionnistes. || publie ensuite, en 1922, Afrikanische Plastik (Berlin: Wasmuth) qui porte sur l'esthétique africaine où il exprime le vœu pionnier de voir travailler ensemble, en bonne harmonie, l'ethnologue et l'historien de l'art. (DEGLI et MAUZE, op. cit, p. 85.) [22]

En l'an 2000, au Pavillon des sessions, où les Musealia sont présentés comme des chefs-d'œuvre occidentaux. [23]

DEGLI et MAUZE, op. cit, p. 109.

\section{[24]}

BOAS, op. cit.

\section{[25]}

<www.sceren.fr/

RevueTDC/841-42087.htm> (consulté en juin 2008). 
[26]

ROY, Claude. Les arts premiers. Paris: R. Delpire, 1965

[27]

BONNAIN, Rolande. L'empire des masques, Les collections d'arts premiers d'aujourd'hui. Paris: Stock, 2001, p. 57-58.

[28]

CLIFFORD, James. Malaise dans la culture, L'ethnographie, la littérature et l'art au XX siècle. Paris: École nationale supérieure des beaux-arts, 1996, p. 203

[29]

L'ethno-esthétique peut être définie comme une discipline ayant pour objet l'esthétique des arts produits dans les groupes sociaux qu'étudie l'ethnologie et plus particulièrement les sociétés sans écriture.

Son but est de dégager les évolutions artistiques dans des aires culturelles afin d'édifier une véritable histoire de l'art.

[30]

DUBUC, Élise. «Entre l'art et l'autre, l'émergence du sujet». In. MEN, op. cit, p. 31-58.

[31]

Ibid.

[32]

Les événements entourant l'exposition The Spirit Sings: Artistic Traditions of Canada's First People, organisée par le Glenbow Museum en 1989, sont reconnus comme une grande rupture dans les relations avec les peuples anciennement colonisés.

Depuis, le partenariat avec les communautés s'accroit. (MEN, op. cit, p. 49-53.) Les partenariats musées-autochtones auraient cependant débuté en 1942, avec le Denver Art Museum. (D'après DUBUC et TURGEON, op. cit, p. 12.)

[33]

HURST, Thomas David. Columbian Consequences. Smithsonian, 1990, 58 p.

DUBUC et TURGEON, op. cit, p. 54 activement à la reconnaissance artistique des objets primitifs, pour lesquels il invente l'expression " arts premiers ". La paternité de cette appellation provient peut-être aussi de Claude Roy, en $1965^{[26]}$. Les Anglo-Saxons privilégient primitive art et les Américains tribal art ${ }^{[27]}$. Ces termes sont également utilisés par les Autochtones. Ces changements lexicologiques témoignent des remises en causes occidentales quant à leurs relations avec les peuples autochtones, mais aussi de la transformation du goût occidental ${ }^{[28]}$.

Parallèlement, dans les années 1960, Jean Laude et Jacqueline Delange créent une discipline, l'" ethno esthétique» ${ }^{[29]}$, qui désigne une nouvelle spécialisation de l'ethnologie. Elle affirme aussi un retour aux codes esthétiques tels qu'ils sont définis par les cultures d'origine. Un deuxième mouvement se renforce, "l'anthropologie de l'art», qui essaie également de réconcilier deux disciplines souvent considérées opposées : l'histoire de l'art et l'ethnologie.

Conscientes de la polysémie des objets, certaines institutions, notamment les musées de sociétés, préferent reconnaître la polyphonie des voix et des discours. Jean Davallon met en place le concept muséographique "d'objet-rébus ", qui consiste à remplacer les mots d'un scénario trop narratif par des objets qui parlent d'eux-mêmes. Le Musée d'ethnographie de Neuchâtel (avec l'Université de la Colombie-Britannique) s'est inspiré de cette idée pour mettre en place une muséographie autour de «l'objet-poème » ${ }^{[30]}$ dans l'exposition temporaire Le musée cannibale de 2002. L'objet exposé s'apparente au calligramme, il signifie par lui-même tout ce qu'il est et tout ce qu'il peut signifier, depuis sa création jusqu'à sa mise en exposition. Michel Ames puis Élise Dubuc proposent une nouvelle approche où l'épistémologie de l'objet laisse place à l'émergence du sujet avec le concept "d'objet-sujet » ${ }^{[311}$. L'autoritarisme du discours occidental et anthropologique est de ce fait minoré et renversé.

De nouvelles approches sont mises en place en Amérique du Nord face aux revendications autochtones où ces derniers participent dorénavant à la production des expositions depuis les années $1980^{[32]}$. Une nouvelle vague de créations d'institutions muséales s'ensuit; elles sont administrées cette fois par les Autochtones eux-mêmes. Les Autochtones d'Amérique du Nord proposent une muséographie dite « cubiste ", par exemple, c'est-à-dire selon différents points de vue. Nous pouvons ici citer David Hurst Thomas et son ouvrage Columbian Consequences ${ }^{[33}$. Ainsi, reconnaissant que toute interprétation est créée par la personne qui l'exprime, il est entendu que seules leur multiplicité et leur diversité permettent d'atteindre une vision composée ${ }^{[34]}$. 


\section{Attribuer un statut aux Musealia dans une exposition}

Les musées détiennent des responsabilités face à leurs collections, face aux publics, mais aussi face à leur histoire quelquefois liée au colonialisme et à la destitution des Musealia de leur peuple d'origine. Chacune de ces responsabilités a été traitée dans le travail dirigé ${ }^{(35)}$, en tenant compte des principes du code de déontologie du Conseil international des musées (ICOM) ${ }^{[36]}$, de divers textes de l'UNESCO ${ }^{[37}$ et du Rapport du Groupe de travail sur les musées et les Premières Nations ${ }^{[38]}$.

S'appuyant sur les rôles et les responsabilités des musées, l'objectif de cette partie est de déterminer le rôle médiatique et le statut de l'objet exposé, soit d'élaborer une grille typologique des muséologies pouvant être mises en place pour les Musealia à partir des muséologies traditionnelles. La grille est ainsi construite à partir du « système art-culture, une machine à fabriquer de l'authenticité» de James Clifford ${ }^{[39]}$, des trois muséologies de Jean Davallon ${ }^{[40]}$, ainsi que d'une muséologie dite " authentique " conceptualisée par Josef Benes ${ }^{[41]}$. L'analyse du rôle de communication de l'objet se base sur les recherches d'Elisio Veron et Martine Levasseur, qui distinguent trois ordres de sens structurant l'univers de la signification ${ }^{[42]}$. Les muséographies d'art et de culture sont regroupées en tant que mise en exposition " exogène $\mathrm{e}^{[43]}$ » et les muséographies de société et de l'authentique sont rassemblées en tant que mise en exposition "endogène", selon les termes de Raymond Montpetit.

\section{Muséologie d'art}

Cette première présentation proviendrait de la tradition des cabinets de curiosités où le musée expose des merveilles, "des œuvres fascinantes, des chefs-d'œuvre fameux ou des singularités remarquables ». Cette mise en scène ne présente pas de contexte particulier, contrairement aux trois autres. L'objet est mis en valeur à partir de son esthétique : aspect formel et iconographique. La stratégie de communication est l'émerveillement. L'objet est souvent présenté dans une vitrine ayant pour seul objectif de le protéger. Létiquette présente l'artiste, la date de création, les matériaux et la provenance. L'objet parle de lui-même, il est à contempler, il est unique. Le domaine du registre de sens est le symbole selon l'ordre linguistique, car l'objet détient en lui-même une nature communicationnelle assez signifiante. Le concept d'exposition privilégie une rencontre entre le visiteur et l'objet. La relation est d'ordre réflexive, ce qui signifie que le visiteur établit lui même un rapport direct et binaire avec un minimum de médiation. Selon les termes de Jean Davallon, l'opérativité symbolique du visiteur entre l'espace synthétique

\section{[35]}

SOULIER, Les musealia des cultures de tradition orale. Rapport de travail dirigé MA en muséologie. Université du Québec à Montréal, 2006, p. 64-106.

[36]

Point 3, articles $3.7,4.3$ et 6.1 . [37]

UNESCO. A Practical Guide to the World Decade for Cultural Development, 19881997, celebrated under the auspices of the United Nations Organization and UNESCO / Guide Pratique de la Décennie mondiale du Développement Culturel, 1988-1997, célébrée sous l'égide de L'ONU et de LUNESCO. Paris: UNESCO, 1987, 95 p.; UNESCO. La Culture et l'avenir. Paris: UNESCO, 1985, 58 p.; UNESCO. Déclaration universelle de l'UNESCO sur la diversité culturelle, adoptée en 2001 ; UNESCO.

La convention sur la protection et la promotion de la diversité des expressions culturelles, adoptée le 20 octobre 2005 à Paris; et la mise en place d'une exposition sur le patrimoine commun, identités plurielles, notre diversité créatrice en 2002. Les principes élaborés par l'UNESCO sont avant tout le respect des libertés fondamentales, la souveraineté des peuples et la mise en valeur des diversités culturelles et des cultures vivantes.

[38]

ASSEMBLEE DES PREMIERES NATIONS et ASSOCIATION DES MUSEES CANADIENS. Rapport du Groupe de travail sur les musées et les Premières Nations, Tourner la page: forger de nouveaux partenariats entre les musées et les Premières Nations. Ottawa: 1994, 21 p. Ce rapport a été rédigé après les controverses provoquées par l'exposition The Spirit Sings, au Canada. 
[39]

CLIFFORD, op. cit, p. 222-228.

[40]

Les trois muséologies décrites par Jean Davallon sont : la muséologie d'objet, de savoir et de point de vue ou d'environnement. Jean Davallon présente ces trois formes de muséologies dans les textes suivants, notamment : DAVALLON, Jean. "L'architecture, objet d'exposition? ?. In. BIDEAU, Alain (dir.). L'architecture : collection, recherche, programmes. Lyon: Les chemins de la recherche, n.38, CCA Montréal,

Centre Jacques Cartier, 1996, p. 71-87.

DAVALLON, Jean.

L'exposition à l'œuvre. Stratégies de communication et médiation symbolique. Paris :

L'harmattan, Communication, 1999, p. 108-115.

DAVALLON, Jean. "Le musée est-il vraiment un média?".

Publics et Musées.

ก. 2, 1992, p. 99-123.

[41]

BENES, Josef. "Variabilité des modes d'exposition *. Museum.

Paris: UNESCO, $n^{\circ} 138$, vol. $35, n^{\circ} 2,1983$, p. 102-107

[42]

VERON, Elisio

et Martine LEVASSEUR. "Le cadre conceptuel $x$, L'espace, le corps, le sens: ethnographie d'une exposition. Paris:

Centre George Pompidou, Bibliothèque publique d'information, 1983, p. 23-38. proposé par l'exposition et le monde utopique du visiteur est beaucoup plus libre et personnelle. Cette muséologie nécessite des connaissances préalables importantes, car le symbole ne se décode qu'à la lumière du savoir. Cette mise en scène est délicate, car le visiteur novice va continuer à entretenir des idées erronées et à répéter des clichés ou des stéréotypes populaires. De plus, cette mise en scène peut être réductrice face à l'immensité des sens des objets. Il est donc nécessaire d'ajouter de l'information sur les valeurs et les sens de l'objet dans sa culture d'origine. Le message peut porter sur le talent de l'artiste et sur la valorisation de la qualité plastique de l'objet, l'élevant au même niveau que les plus grands chefs-d'œuvre occidentaux. Un rapport au sacré découle également de cette mise en valeur. Il est pertinent d'expliquer les valeurs spirituelles et mythologiques de cette forme d'expression. Le statut de l'objet serait donc une œuvre.

\section{Muséologie de culture}

Héritée du siècle de la Science, le XIX ${ }^{e}$ siècle, cette muséographie a pour objectif premier de transmettre un savoir ethnologique et/ou anthropologique. Elle présente un contexte suggéré en fonction des objectifs didactiques. La mise en scène valorise les caractéristiques culturelles de l'objet exprimant un message scientifique. L'objet se trouve ainsi dans une représentation artificielle de la réalité. Il donne à comprendre la culture. L'étiquette décrit la culture d'origine, la période de création, les matériaux, la provenance, la valeur de l'objet dans sa culture et son mode d'utilisation. L'objet ne parle pas de lui-même, il est à présenter avec des outils de médiation comme des panneaux ou des interactifs. L'objet représente des faits coutumiers ou culturels, il n'est pas unique. Le domaine du registre de sens est l'icône selon l'ordre analogique, car les signifiants de l'objet représentent des habitus culturels. Le concept d'exposition privilégie la communication d'un message scientifique au visiteur à partir de l'impact visuel de l'objet. La relation est d'ordre transitif, ce qui signifie que le visiteur établit un rapport avec l'objet grâce à l'information apportée en complément. L'opérativité symbolique du visiteur entre l'espace synthétique proposé par l'exposition et le monde utopique du visiteur est orientée et guidée. Le visiteur n'est pas libre dans son interprétation. Cette muséologie des sciences est directement liée à une approche disciplinaire. Les connaissances préalables des visiteurs dépendent du concept d'exposition et de la vulgarisation scientifique mis en place. Mais cette vulgarisation doit offrir différents niveaux d'interprétation pour les connaisseurs et pour les amateurs. Les premiers seront en mesure d'apprécier les méthodes et les fondements épistémologiques, les derniers 
en comprendront les résultats. Le statut de l'objet serait donc une illustration de la théorie scientifique expliquant tant la démarche scientifique que les phénomènes culturels analysés.

\section{Muséologie de société}

Cette muséologie serait fille de la postmodernité. Elle a pour objectif premier de présenter une thématique ou une problématique. Le concept d'exposition est davantage axé sur les publics. Elle présente un contexte suggéré et/ou analogique ${ }^{[44]}$ en fonction des objectifs communicationnels. La stratégie de communication se réalise à partir d'une perspective directrice guidant le récit thématique. La disposition des éléments dans l'exposition tente de répondre à la question latente sur l'identité. Il y a deux axes dans lesquels le visiteur se confronte pendant tout son parcours et qui définissent l'identité sous son aspect tangible et symbolique : l'axe du réel fondé sur des faits et l'axe de l'imaginaire fondé sur ce que le visiteur peut se créer. Deux unités s'ajoutent à ces deux vecteurs: l'unité d'immersion spatiotemporelle - pour répondre aux questions où sommes-nous et d'où venons-nous? - et l'unité concernant l'identification intra et interculturelle - pour répondre aux questions qui sommes-nous et qui sommes-nous par rapport aux autres? Dans les zones d'immersion, le visiteur se retrouve, il reconnait ce qu'il voit et il enrichit également ses connaissances. L'objet peut représenter ce qui peut être attendu par le visiteur ${ }^{[451}$. Mais il est ensuite nécessaire de l'emmener dans un espace de découverte, afin de ne pas répéter les stéréotypes qui persistent depuis la colonisation. Le visiteur se retrouve alors dans des zones d'identification face à un monde inconnu où il est confronté à ce qu'il n'est pas. La mise en scène valorise la complexité de l'universalité et de l'altérité. L'objet donne à se comprendre face aux points communs et aux différences qu'il montre entre les sociétés. L'étiquette présente la culture d'origine, la période de création, les matériaux, la provenance, ses valeurs ou son utilisation dépendamment de la thématique de l'exposition. L'objet peut parler de lui-même, mais il est aussi mis en dialogue avec d'autres objets. Il peut également être présenté avec des outils de médiation comme des panneaux explicatifs ou interrogatifs. Le domaine du registre de sens est la métonymie, car le signifiant a des rapports existentiel et indiciel avec ce qu'il signifie. Le concept d'exposition privilégie la mise en réflexion du visiteur à partir de l'impact visuel de l'objet. La relation est d'ordre inclusif, ce qui signifie que le visiteur établit un rapport avec l'objet grâce à l'information apportée en complément et par rapport à lui-même et à ses propres convictions. L'opérativité symbolique du visiteur entre son monde utopique et l'espace synthétique proposé par l'exposition est légèrement orientée.

\section{[43]}

MONTPETIT, Raymond.

* Une logique d'exposition populaire: les images de la muséographie analogique*.

Publics et Musées. Lyon

Presses universitaires de Lyon, n 9, janvier-juin 1996,

p. 87. Une mise en exposition référentielle ou exogène "concrétise des logiques établies par un savoir particulier, constitué hors d'elle. La disposition de l'exposition fait voir comment un savoir disciplinaire structure et analyse ses objets d'études." [44]

La présentation analogique peut présenter un espace imaginaire ou bien réel, à la différence de la définition de Montpetit. Cet espace peut ne pas exister, mais il répond à une vision ancrée dans un inconscient collectif ou dans des présupposés populaires. [45]

Le chargé de projets peut considérer la demande du public grâce à des enquêtes préalables, afin d'être en adéquation avec ce qu'il pense. Le monde utopique du visiteur est en quelque sorte mis en scène. II peut directement entrer dans cet univers. 
Le visiteur est semi-libre dans son interprétation. Cette muséologie de société demande des connaissances préalables liées aux faits actuels et historiques car elle met en corrélation différentes sociétés et elle interroge directement le visiteur. Mais elle peut être accessible à tous les publics grâce aux outils d'interprétation orientant et soutenant le visiteur dans sa négociation. Le statut de l'objet serait donc une interrogation ou une mise en relation intrigante et constructive pour la société.

FIGURE 1

Approche de communication dans une muséographie de société

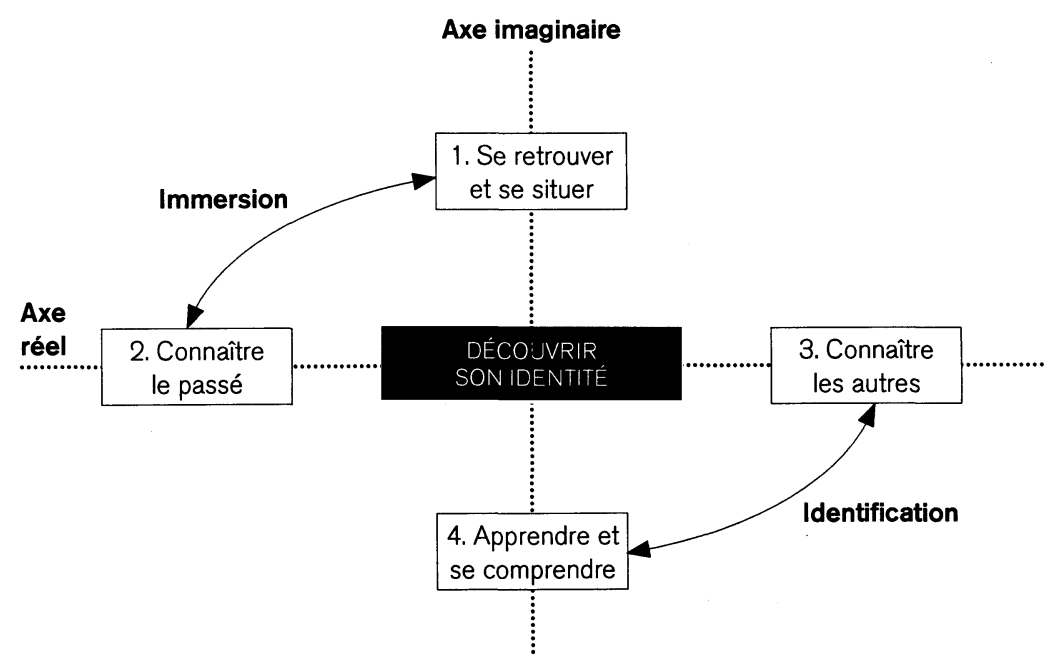




\section{Muséologie de l'authentique}

L'esprit de cette muséologie remonterait aux premières expositions depuis les grandes découvertes et a toujours été latent dans les expositions mettant en valeur l'exotisme des Musealia. Cette muséologie est fondée sur les différences, l'altérité et la dichotomie entre les occidentaux et les autres. Mais les principes muséographiques seraient fils de la modernité et de la "nouvelle muséologie». La muséologie de l'authentique hériterait des principes scénographiques des écomusées. Elle a pour objectif premier de présenter une reconstitution d'une réalité lointaine. Elle est axée sur l'objet et ses sens premiers; les objets sont sélectionnés en fonction de leurs potentialités à exposer un univers totalement inconnu pour les visiteurs. Elle présente un contexte analogique en lien avec les fonctions et les valeurs originelles de l'objet dans son environnement premier. Le domaine du registre de sens est l'icône, car l'objet est dans un contexte de représentation et d'analogie avec la réalité authentique.

La stratégie de communication se réalise à partir d'un maintien des relations entre les objets et leur environnement, selon leurs utilisations premières. Les liens entre les éléments sont conservés sans qu'il y ait besoin d'outils de médiation supplémentaires. La scénographie est très importante. C'est l'aménagement de l'ensemble des objets qui a un rôle premier et qui exerce un effet direct sur les visiteurs. Ces derniers sont en contact direct avec un univers inconnu. Leur rôle de participation est minime, car ils sont directement plongés dans cette réalité, sans faire d'effort d'imagination ou d'appel à des connaissances spécifiques. Les fonctions des objets et leurs valeurs doivent se comprendre immédiatement par la mise en scène et l'impact visuel. Les objets donnent à se comprendre dans cette organisation descriptive. L'opérativité symbolique du visiteur entre son monde utopique et l'espace synthétique proposé par l'exposition est totalement orientée. Le visiteur n'est pas libre dans son interprétation. La relation est d'ordre inclusif, car il établit un rapport avec les objets dans l'organisation spatiale. L'étiquette présente la culture d'origine, la période de création, les matériaux, la provenance, la fonction. Cette présentation met en valeur l'authenticité des objets et valorise l'aspect traditionnel de ces cultures non occidentales. Les unités d'immersion exposent l'Altérité sans aucun lien ou contact avec le monde occidental. Les objets ne présentent aucune empreinte d'acculturation. Le risque de cette muséographie est de retomber dans les recherches des bizarreries et des curiosités ou dans un idéal rousseauiste. Elle doit être mise en place en fonction d'une interdisciplinarité des sciences humaines qui mettent avant tout en valeur une thématique en lien avec la culture des objets et non en fonction de leur propre science. L'objet est ainsi exposé dans ses atouts authentiques. Son statut est un objet authentique. 


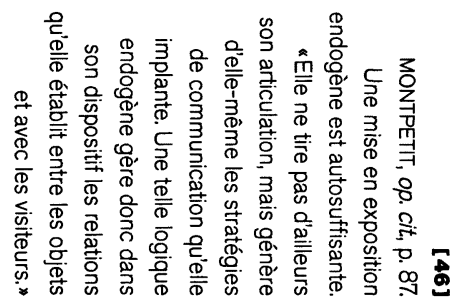

\begin{tabular}{|c|c|c|c|c|}
\hline & \multicolumn{2}{|c|}{ MISE EN EXPOSITION EXOGÈNE } & \multicolumn{2}{|c|}{ MISE EN EXPOSITION ENDOGĖNE ${ }^{[46]}$} \\
\hline & Muséographie d'art & $\begin{array}{l}\text { Muséographie } \\
\text { de culture }\end{array}$ & $\begin{array}{l}\text { Muséographie } \\
\text { de société }\end{array}$ & $\begin{array}{l}\text { Muséographie } \\
\text { de l'authentique }\end{array}$ \\
\hline $\begin{array}{l}\text { MODALITÉ DE } \\
\text { FONCTIONNEMENT }\end{array}$ & $\begin{array}{l}\text { - L'objet est rencontré } \\
\text { par le visiteur }\end{array}$ & $\begin{array}{l}\text { - Le savoir sur la culture } \\
\text { est présenté au visiteur }\end{array}$ & $\begin{array}{l}\text { - Le visiteur traverse un } \\
\text { point de vue, une } \\
\text { thématique et/ou } \\
\text { ne problématique en } \\
\text { lien avec sa société }\end{array}$ & $\begin{array}{l}\text { - Un univers inconnu } \\
\text { est exposé aux visiteurs } \\
\text { "occidentaux" }\end{array}$ \\
\hline $\begin{array}{l}\text { CONTEXTE ET UNITÉ } \\
\text { DE PRÉSENTATION }\end{array}$ & $\begin{array}{l}\text { Dans une vitrine, } \\
\text { neutre, objet isolé }\end{array}$ & $\begin{array}{l}\text { - Contexte culturel } \\
\text { suggéré, panneau } \\
\text { ou interactif }\end{array}$ & $\begin{array}{l}\text { Contexte suggéré } \\
\text { ou analogique, } \\
\text { séquence d'exposition, } \\
\text { objet en dialogue avec } \\
\text { d'autres objets }\end{array}$ & $\begin{array}{l}\text { - Reconstitution d'un contexte } \\
\text { originel se différenciant } \\
\text { des habitudes occidentales } \\
\text { à partir d'objets dans un } \\
\text { temps et une culture } \\
\text { déterminés et arrêtés }\end{array}$ \\
\hline $\begin{array}{l}\text { LOGIQUE DE } \\
\text { COMMUNICATION }\end{array}$ & $\begin{array}{l}\text { - Contemplation, } \\
\text { rencontre avec } \\
\text { le visiteur } \\
\text { - Le visiteur } \\
\text { admire }\end{array}$ & $\begin{array}{l}\text { - Communication } \\
\text { d'un savoir } \\
\text { - Le visiteur apprend } \\
\text { en suivant l'exposition }\end{array}$ & $\begin{array}{l}\text { - Identification et } \\
\text { immersion dans } \\
\text { l'universel et l'altérité } \\
\text { - Participation active } \\
\text { du visiteur } \\
\text { - Le visiteur apprend } \\
\text { par lui-même et } \\
\text { se comprend }\end{array}$ & $\begin{array}{l}\text { - Immersion totale } \\
\text { dans l'altérité } \\
\text { - Participation minime } \\
\text { du visiteur qui comprend } \\
\text { en regardant }\end{array}$ \\
\hline
\end{tabular}




\begin{tabular}{|c|c|c|c|c|}
\hline & \multicolumn{2}{|c|}{ MISE EN EXPOSITION EXOGÈNE } & \multicolumn{2}{|c|}{ MISE EN EXPOSITION ENDOGĖNE } \\
\hline & $\begin{array}{l}\text { Muséographie } \\
\text { d'art }\end{array}$ & $\begin{array}{l}\text { Muséographie } \\
\text { de culture }\end{array}$ & $\begin{array}{l}\text { Muséographie } \\
\text { de société }\end{array}$ & $\begin{array}{l}\text { Muséographie } \\
\text { de l'authentique }\end{array}$ \\
\hline $\begin{array}{l}\text { RÔLE DE } \\
\text { COMMUNICATION }\end{array}$ & $\begin{array}{l}\text { - Symbole, objet parlant } \\
\text { de lui-même }\end{array}$ & - Icône & $\begin{array}{l}\text { Métonymie } \\
\text { (présentant une partie } \\
\text { de son signifié) }\end{array}$ & - Icône \\
\hline $\begin{array}{l}\text { MATRICE } \\
\text { COMMUNICATIONNELLE }\end{array}$ & - Réflexive & - Transitive & - Inclusive & - Inclusive \\
\hline $\begin{array}{l}\text { SIGNIFIANTS } \\
\text { ET QUALIFIANTS }\end{array}$ & $\begin{array}{l}\text { Valeurs esthétiques, } \\
\text { aspects formel } \\
\text { et iconographique } \\
\text { autosuffisants }\end{array}$ & $\begin{array}{l}\text { Potentiel d'illustration } \\
\text { et de représentation } \\
\text { de la théorie scientifique }\end{array}$ & $\begin{array}{l}\text { - Potentiel d'évocation } \\
\text { du concept d'exposition }\end{array}$ & $\begin{array}{l}\text { Potentiel de représentation } \\
\text { d'une réalité originelle, } \\
\text { d'intégration dans une } \\
\text { organisation spatiale et } \\
\text { d'illustration de ses propres } \\
\text { fonctions premières }\end{array}$ \\
\hline STATUT & - Euvre, objet unique & $\begin{array}{l}\text { - Témoin, objet courant } \\
\text { dans la culture d'origine } \\
\text { de l'objet }\end{array}$ & $\begin{array}{l}\text { - Interrogateur car } \\
\text { universel et différent }\end{array}$ & - Objet authentique \\
\hline PUBLIC CIBLE & $\begin{array}{l}\text { - Connaissances en } \\
\text { histoire et en art }\end{array}$ & $\begin{array}{l}\text { - Avisé, non avisé } \\
\text { mais intéressé }\end{array}$ & $\begin{array}{l}\text { Culture générale, } \\
\text { connaissances en } \\
\text { histoire et au courant } \\
\text { de l'actualité }\end{array}$ & $\begin{array}{l}\text { - Avisé, non avisé } \\
\text { mais curieux }\end{array}$ \\
\hline
\end{tabular}


Cette typologie n'est pas exclusive; les quatre muséologies se combinent pour offrir des messages et des stratégies de communications pluriels et afin de s'adresser à des publics hétérogènes dans des sociétés cosmopolites.

\section{Les Musealia sont-ils toujours de l'art?}

Les statuts des objets sont analysés à partir des approches disciplinaires des musées, des approches de recherche des conservateurs, de la taxinomie à l'interne des collections et dans les expositions, où ils sont évalués à partir de la typologie élaborée précédemment.

Il en résulte que, contrairement à ce qu'on pourrait croire, certains liens ne vont pas de soi.

Il n'y a pas de corrélation entre les approches disciplinaires des musées et les statuts des objets en exposition. Il n'y a aucune unité, non plus, entre les perspectives des musées. À titre d'exemple, le Musée McCord d'histoire canadienne, dans son exposition sur les haïdas, a présenté les objets comme des œuvres d'art. Il a travaillé en étroite collaboration avec l'artiste Robert Davidson qui a proposé de mettre en valeur la collection haïda du géologue George Mercer Dawson, créant, de ce fait, une histoire de l'art haïda qui introduisait et expliquait ses propres créations artistiques contemporaines. De même, le Musée des civilisations présente certains objets comme des œuvres d'art si les créateurs les ont produites dans cette visée. Par contre, le Musée national des beaux-arts du Québec, le Musée des beaux-arts de Montréal et le Musée des beaux-arts du Canada mettent toujours en place des muséologies d'art, même si les conservateurs ne sont pas unanimes sur le statut d'œuvre des objets de la côte nord-ouest, contrairement aux objets inuit. Enfin, le Musée d'art contemporain de Montréal ne présente pas de Musealia et ne considère pas ces objets comme des œuvres d'art, pas même les objets inuit.

On se rend également compte d'un certain décalage concernant le système de classification en conservation et en exposition dans les musées de beaux-

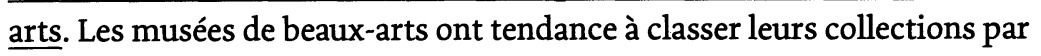
période historique, alors que les Musealia sont tous regroupés dans un même département sans différenciation temporelle. Le département «Art ancien avant 1850 " du Musée national des beaux-arts de Québec regroupe la collection d'art contemporain inuit et les autres collections autochtones. De même, le Musée des beaux-arts de Montréal regroupe les Musealia dans le département « Art canadien et art religieux de l'Ancien Régime jusqu'en 1945 ". Le Musée des beaux-arts du Canada insiste quant à lui sur la mise en valeur et la reconnaissance des Musealia comme étant des œuvres d'art, 


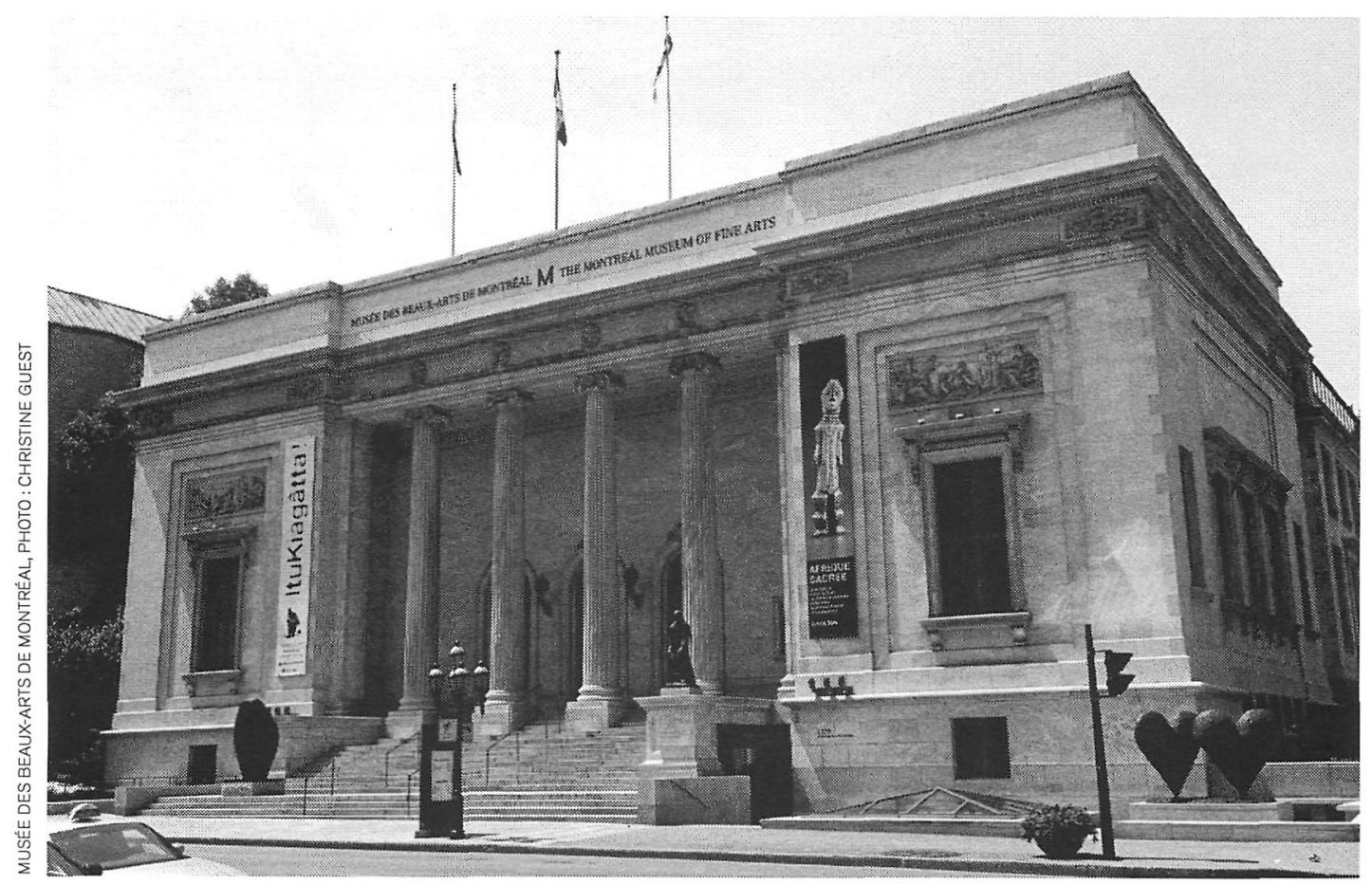

alors que l'institution ne détient pas d'objets anciens dans ses collections. Ces constats démontrent une certaine marginalisation de ces objets au sein même de ces institutions artistiques.

Il n'y a pas de lien entre les classements et les catégories proposés dans les catalogues des musées et les statuts donnés aux objets dans les expositions. Par exemple, le Musée McCord et le Musée canadien des civilisations s'intéressent aux zones géoculturelles et la classification des objets est faite par rapport à la fonction première de l'objet, ce qui en exclut la dimension artistique. Le Musée canadien des civilisations, pour sa part, retient aussi la nature de l'œuvre pour classifier la collection inuit.

Des contradictions supplémentaires apparaissent en mettant en relation les muséologies qui présentent les collections d'art contemporain inuit avec les $\underline{\text { muséologies qui exposent les œuvres contemporaines de la côte nord-ouest }}$ et celles qui montrent les autres artistes canadiens dans les expositions permanentes. Les musées des beaux-arts de Montréal et le Musée des beaux-arts du Canada présentent les collections inuit en combinant une muséologie d'art, de culture et de société. Ils donnent des repères géochronologiques et présentent des témoignages d'Inuit. Ces mêmes musées exposent les objets contemporains de la côte nord-ouest seulement dans une muséologie d'art. À l'inverse, le Musée canadien des civilisations expose les objets contemporains inuit et de la côte nord-ouest uniquement dans des muséologies d'art. 
Il n'y a pas réellement d'explication vraisemblable par rapport à la date de création des objets, même si quelquefois une rupture est faite autour du milieu du XX ${ }^{e}$ siècle, car le Musée des beaux-arts de Montréal présente les objets anciens de la côte nord-ouest comme des œuvres d'art et les œuvres contemporaines inuit ne sont pas présentées comme les œuvres contemporaines du reste du Canada. Elles ne sont pas exposées, par exemple, d'après un · concept monographique promulguant un seul artiste, comme il est d'usage pour les artistes contemporains. Elles sont toujours présentées comme provenant d'un collectif, en mettant en valeur de manière très limitée et ponctuelle les talents de chacun des artistes.

Ces quelques remarques montrent qu'il n'y a pas de constance ni de logique apparentes et que ces collections ne trouvent pas tout à fait leur place

Notion conçue par le philosophe russe Mikhail Bakhtine en littérature, pour désigner la relation mutuelle entre l'espace et le temps et présenter le temps et le lieu de l'action, et définie en ces termes par James Clifford (op. cit., p. 234): «qui indique une configuration d'indicateurs spatiaux et temporels dans un cadre fictionnel où (et quand) prennent place certaines activités et certaines histoires".

[51] CLIFFORD, op. cit, p. 244-249. dans les musées d'art, même s'il y a une tendance à valoriser les Musealia dans les expositions en tant qu'œuvres d'art dans l'ensemble des musées. Les discours à l'interne des musées reflètent les anciennes visions disciplinaires et les chevauchements des traditions d'établissement. James Clifford démontre, dans son ouvrage Malaise dans la culture, l'interprétation subjective de ces collections " historiquement contingentes et sujettes à une réappropriation locale " ${ }^{[47]}$. Pour lui, l'art " est une catégorie culturelle occidentale mouvante " ou "intemporelle " ${ }^{[48]}$ trouvant ses origines dans le primitivisme moderniste où les sentiments humanistes marchent main dans la main avec le sens esthétique et avec un marché spécialisé dans l'art tribal qui tend à nier " aux cultures et aux artistes tribaux toute faculté d'invention" ${ }^{[49]}$.

Par contre, il en ressort aussi que les expositions les plus récentes combinent davantage la muséologie d'art avec la muséologie de culture et valorisent les cultures vivantes.

L'objet polysémique est mis en valeur selon un consensus entre l'institution et ses partenaires autochtones. On pourrait se demander si l'on peut parler d'un métissage muséologique. De manière générale, les musées présentent les objets dans leur complexité polysémique afin de rendre la parole aux œuvres et aux Premières Nations. Les muséologies mettent en valeur les qualités esthétiques des objets tout en orientant les visiteurs vers plusieurs interprétations de l'objet. Seules les muséographies d'art ignorent le plus souvent les valeurs et les sens cumulatifs des objets.

Finalement, ce n'est pas le lieu d'exposition qui donne un statut à l'objet, mais c'est l'histoire de l'objet ou l'élaboration d'un "chronotope " ${ }^{[50]}$, selon l'expression de Mikhail Bakhtine, la vision du conservateur et l'influence des collaborations avec les Autochtones. Comme le suggérait Clifford, il faut innover sur d'autres formes d'appropriations en écoutant les communautés actuelles qui font parler les objets dans une temporalité et une contextualité différentes ${ }^{[51]}$. 
[52]

DE VARINE, Hugues.

"Éthique et patrimoine.

La décolonisation de la

muséologie». Les nouvelles de I'ICOM, n’ 3, 2005.

[53]

DUBUC et TURGEON,

op. cit p. 11 ou

$<$ http://www.ant.ulaval.ca/

anthropologieetsocietes/

2004-2presentation.htmD

(consulté en février 2007).

[54]

Radio France Internationale.

"Des sanctuaires aux musées:

collections et marché de l'art

primitif». Regard sur l'humanité

Émission diffusée en douze parties lors de linauguration

du Musée du quai Branly,

de $13 h$ à $14 h, 2006$.

<http://www.rfi.fr/actufr/ pages/001/page_149.asp>

(consulté à l'été 2006).

[55]

LENCLUD, Gérard.

"Qu'est-ce que la tradition?

Transcrire les mythologies.

Paris: Bibliothèque Albin Michel, 1994, p. 25-44.

\section{[56]}

«Un mot-outil est un mot qu'on utilise sans trop penser à son sens. Il est une procédure grossière d'identification *. (Id, p. 25.)

\section{[5]}

"Un mot-problème est un mot-outil sur lequel on s'est arrêté. On s'y est arrête parce qu'on s'est avisé que ses emplois ne correspondaient pas à une notion précise ou parce qu'on s'est aperçu qu'il servait à designer des choses différentes entre elles, même pas toujours pourvues d'un air de famille [...] La chose visée par le mot-outil en perd sur-le-champ la qualité d'objet naturel (ou naturalisé); le sentiment d'évidence se dissout. * (Id., p. 25.)

[58]

Je remercie Diane Joly, doctorante en histoire de l'art à l'Université du Québec à Montréal, de cette suggestion de lecture. 


\section{Summary}

\section{The Status of Musealia from Cultures of Oral Tradition}

[Translated by Allana Carlyle]

[59]

Musealia, in French muséalie, is a term of Latin origin proposed in 1970 by Zbyneck Stransky to represent the equivalent of a museum object. More recently, the term was used in a more philosophic perspective by J.L. Déotte as he discussed suspense. (DE BARY et TOBELEM,

op. cit, p. 236-237.

[60]

POULOT, Dominique. Musée et muséologies. La Découverte, Paris, Collections "Repères", 2005, p. 82.

[61]

Underlining the fact that these collections were selected, acquired, and conserved by museum-related institutions and that the objects were collected in territories which share this oral tradition.

[62]

The successive status of museum objects can thus be presented concisely: "Rare artefacts from savages" in cabinets of curiosities in Natural History museums; "primitive specimens illustrating evolution" in ethnographic museums; "cultural artefacts" in anthropology museums; and "early art" in art museums.

[63]

MEN, op. cit, p. 54

[64]

DUBUC and TURGEON, op. cit, p. 11
The era of post-colonialism has generated memory work, questioning, and challenges in anthropology, concerning objects from Oceania, Africa, and the Americas, which have been preserved and exhibited in Euro-North American museums. Museum discourse has entered the era of suspicion and a "museography of estrangement," according to the expression used by Dominique Poulot in reference to the exhibit entitled Le museé cannibale presented at the Musée d'ethnographie de Neuchâtel. ${ }^{[00]}$ An essential question is being asked in museums: How do we qualify, classify, and exhibit cultural goods which have been despoiled or given to museums by formerly colonized populations? In the framework of this research, these objects are designated as "musealia from cultures of oral tradition" (MCOT), a new epithet proposed by the author. ${ }^{\left[{ }^{[1]}\right]}$ This term does not express an opinion or a particular interpretive or economic theory of artistic or anthropological discipline, even if it raises the fact that it originates from and represents a culture; it is more and more currently used in the field.

The history of the status of MCOTs and of their successive movement within different types of museums reveals Occidentals' diverging opinions and scientific interests regarding these populations, from the $15^{\text {th }}$ century until today. ${ }^{[62]}$

Since the 1960s, European museums have attempted to neutralize the walls of their institutions, impregnated with imperialism. Beginning in the 1980s, North American museums opened their doors to the views of the First Nations. Today, MCOTs are interpreted through a multidisciplinary approach and are seen as polyfunctional and polysemous objects. They are also seen as "cubist" ${ }^{\left[{ }^{33]}\right.}$ or "plurivocal" ${ }^{[64]}$ in North America. Museums, therefore, prefer to combine different points of view or to consider the position of the native populations in order to see the emergence of the different meanings of these MCOTs and then present an integrated vision.

The question of authority sharing is still a current one, in view of the threat of cultural standardization through globalization. Globalization has set in motion the renewal of the singularisation of non-Western populations and has promulgated the revendication of these populations for the possession of their heritage and a 
right to a voice on the subject of their representation in museum-related institutions. Museums participate in this process of recognition of the living culture of the Native People, the diversity of their cultural expressions, and the plurality of the meanings of the MCOTs. ${ }^{[65]}$

Based on recommendations by the International Council of Museums (ICOM), by the United Nations Educational, Scientific and Cultural Organization (UNESCO), and by museums reports, this analysis concerns the current roles, responsibilities, and issues which lay at the heart of museums during their allocation of status to MCOTs.

Due to the tendency of "artialising" ${ }^{[6]}$ MCOTs, a phenomenon noticed specifically at the Musée du quai Branly in Paris, and also due to the debate between art and culture, a survey was undertaken in Eastern Canada in order to study the status of the objects in these museums which contribute systematically with the First Nations living in situ. The goal of the research was to identify the types of museums possessing objects of Amerindian and Inuit origin and to analyse the status of these objects (conservation and importance), all in the context of the internal workings of the museum as well as in external mediations. These perspectives were placed in relation to the art-culture system of James Clifford. ${ }^{[67]}$ Meetings and formal exhibition analysis took place in several museums presenting native collections in order to understand the determining factors in the status of MCOTs and to establish a typology of these statuses.

The result is a mosaic of contradictions within the museum, linked to the institution's tradition and to the well-known divergence between disciplinary museums and society museums. The statuses differ between fine arts museums and museums of civilization. A certain uniformity nonetheless appears in the process of cultural recognition of the First Nations, which differs clearly from the perspectives of the musée du quai Branly, where a more artistic approach is applied towards their objects. in 2001, UNESCO Convention for the Safeguarding of the Intangible Cultural Heritage, adopted in 2003, ICOM Deontological Code and Le rapport du Groupe de travail sur les musées et les Premières Nations sponsored by the Assembly of First Nations and the Association of Canadian Museums in 1992.

\section{[66]}

The term artialisation, which means putting forward aesthetic values, was used during a conference entitled "History of Art and Anthropology" held at the musée du quai Branly in Paris from June $21^{\text {st }}$ to $23^{\text {rd }}$ of, 2007 , to qualify the interventions of art historians and their interpretations of African, Oceanian, and American artefacts, as well as the phenomenon occurring within museums containing such artefacts.

[67]

CLIFFORD, op. cit, p. 215-248. 